\title{
Analisis Tarif INA-CBGs Pasien Hipertensi Rawat Inap di Rumah Sakit Umum Daerah Panembahan Senopati
}

\author{
Anis F. Nilansari ${ }^{1}$, Nanang M. Yasin ${ }^{2}$, Diah A. Puspandari ${ }^{3}$ \\ ${ }^{1}$ Program Sarjana Farmasi, Fakultas Sains dan Teknologi, Universitas PGRI Yogyakarta, \\ Bantul, Indonesia, ${ }^{2}$ Fakultas Farmasi, Universitas Gadjah Mada, Yogyakarta, Indonesia, \\ ${ }^{3}$ Fakultas Kedokteran Kesehatan, Masyarakat dan Keperawatan, \\ Universitas Gadjah Mada, Yogyakarta, Indonesia
}

\begin{abstract}
Abstrak
Angka pengidap hipertensi pada tahun 2018 sebesar 34,1\% dari penduduk Indonesia. Profil data kesehatan Indonesia menyebutkan bahwa secara nasional terjadi peningkatan prevalensi hipertensi dari $25,8 \%$ pada tahun 2013 menjadi 34,1\% pada tahun 2017. Biaya pasien hipertensi rawat inap di rumah sakit yang bergabung dengan Asuransi Kesehatan JKN diklaim berdasarkan tarif Indonesian-Case Based Groups (INA-CBGs). Penelitian ini bertujuan untuk mengetahui besar perbedaan biaya riil rumah sakit dengan tarif INA-CBGs di Rumah Sakit Umum Daerah (RSUD) Panembahan Senopati menggunakan analisis deskriptif pada perspektif penyedia pelayanan kesehatan yaitu rumah sakit. Pengambilan data biaya medis langsung dilakukan secara retrospektif. Objek pada penelitian ini adalah berkas keuangan rumah sakit dan rekam medis periode Oktober 2016-Juli 2017 RSUD Panembahan Senopati. Sebanyak 53 pasien menjadi sampel penelitian ini. Data dianalisis menggunakan one sample t-test untuk membandingkan biaya riil rumah sakit dengan tarif INA-CBGs. Hasil penelitian menunjukkan besarnya perbedaan antara biaya riil dengan tarif INA-CBGs yaitu sebesar negatif Rp30.993.964. Terdapat perbedaan bermakna antara besar biaya riil yang dikeluarkan rumah sakit terhadap tarif INA-CBGs pada pasien kelas 1 dengan nilai signifikansi $\mathrm{p}<0,05(0,039)$. Persentase total biaya rumah sakit yang digunakan untuk komponen biaya obat yaitu sebesar $26,3 \%$. Simpulan dari penelitian ini adalah rumah sakit dapat mengalami kerugian karena biaya yang dikeluarkan lebih besar dibandingkan tarif klaim INA-CBGs.
\end{abstract}

Kata kunci: Biaya pasien, hipertensi, INA-CBGs, JKN, rumah sakit

\section{Analysis of INA-CBGs Rates of Hypertensive Inpatients in Panembahan Senopati Hospital}

\begin{abstract}
The number of people with hypertension reached $34.1 \%$ of the Indonesian population in 2018 . According to the Indonesian health profile data, an increase from $25.8 \%$ in 2013 to $34.1 \%$ in 2017 in the prevalence of hypertension nationally was observed. The costs of hypertensive inpatients in hospitals joining the JKN Health Insurance were claimed based on Indonesian-Case Based Groups (INA-CBGs) rates. The purpose of this study is to determine the difference between real costs of hospitals and INA-CBGs rates in Panembahan Senopati Hospital. A descriptive analysis based on the perspective of health care providers was conducted and retrieval of medical costs data was done directly. The hospital financial sheets and medical records between October 2016-July 2017 were used as objects of this study. Furthermore, the samples of this study included a total of 53 patients and analysis of data was achieved using the one sample t-test to compare real hospital costs with INA-CBG rates. The results showed a large difference between the real cost and INA-CBG rates, which was negative Rp30,993,964. There was a significant difference between hospital's real costs incurred by hospitals and the INA-CBG rates for grade 1 patients with a significant value of $\mathrm{p}<0.05(0.039)$. The percentage of total hospital costs used for the component costs of drugs was $26.3 \%$. This study concludes that hospitals can suffer losses because the costs incurred are more significant than the INA-CBGs claim rates.
\end{abstract}

Keywords: Hospitals, hypertension, INA-CBGs, JKN, patients cost

Korespondensi: apt. Anis F. Nilansari, M.Pharm.Sci., Program Sarjana Farmasi, Fakultas Sains dan Teknologi, Universitas PGRI Yogyakarta, Bantul, Daerah Istimewa Yogyakarta 55182, Indonesia, email: anis@upy.ac.id Naskah diterima: 14 November 2019, Diterima untuk diterbitkan: 26 Januari 2021, Diterbitkan: 30 Maret 2021 


\section{Pendahuluan}

Hipertensi merupakan penyakit yang ditandai dengan adanya peningkatan tekanan darah hingga angka lebih dari 140/90 $\mathrm{mmHg}$ secara persisten. Tren peningkatan prevalensi hipertensi telah ditunjukkan di negara-negara dengan penduduk berpenghasilan tinggi, rendah dan menengah. Sebanding dengan tren global, salah satu penyebab kematian paling utama di Asia Tenggara adalah hipertensi dengan kecenderungan prevalensi yang mengalami peningkatan. ${ }^{1}$

Hipertensi menjadi kontributor keempat kematian dini di negara maju dan ketujuh di negara berkembang. Data terbaru menunjukkan bahwa hampir 1 miliar orang dewasa (lebih dari seperempat populasi dunia) menderita hipertensi pada tahun 2000, dan hal ini diperkirakan akan meningkat menjadi 1,56 miliar pada tahun $2025 .^{2}$

Data kesehatan di Indonesia tahun 2017 menunjukkan bahwa prevalensi hipertensi pada tahun 2013 sebesar $25,8 \%$, meningkatmenjadi $34,1 \%$ pada tahun $2017 .{ }^{3}$ Data Kementerian Kesehatan Republik Indonesia menyebutkan bahwa biaya Badan Penyelenggara Jaminan Sosial (BPJS) sejak 2015 sebanyak 30 persen diserap oleh pengobatan penyakit kronis seperti diabetes, hipertensi, dan jantung dengan biaya mencapai 6,9 triliun. Hal ini dapat terjadi sebab penyakit-penyakit ini dimiliki oleh hampir satu juta penduduk Indonesia. ${ }^{4}$

BPJS memberlakukan pelaksanaan jaminan kesehatan masyarakat dengan menggunakan sistem Jaminan Kesehatan Nasional (JKN) yang dimulai sejak tanggal 1 Januari 2014. Sistem JKN memberlakukan tarif pelayanan kesehatan yakni dengan cara penentuan tarif Indonesian-Case Based Groups (INACBGS). Pembayaran yang dilakukan dengan menggunakan sistem INA-CBGS ialah baik rumah sakit maupun pihak pembayar tidak lagi merinci tagihan berdasarkan rincian pelayanan yang diberikan, melainkan hanya dengan menyampaikan diagnosis pasien dan kode Disease Related Group (DRG) atau disebut sebagai koding. ${ }^{5}$

Berdasarkan Peraturan Menteri Kesehatan Nomor 76 Tahun 2016 tentang petunjuk teknis sistem INA-CBGs, metode pembayaran yang ditetapkan oleh BPJS berdasarkan metode prospektif casemix INA-CBGs. ${ }^{6}$ Adanya sistem pembayaran dengan memberlakukan metode prospektif tersebut maka besaran tarif ditetapkan sebelum pelayanan kesehatan diberikan kepada pasien. Tarif yang diberikan sudah mencakup seluruh jenis perawatan, yaitu mulai pasien masuk rumah sakit sampai keluar rumah sakit. Satu kode pada sistem INA-CBGs sudah termasuk dalam biaya obat, biaya tindakan, bahan medis habis pakai, dan biaya akomodasi. ${ }^{7}$

Besarnya tarif INA-CBGs kode I-4-171 untuk pasien rawat inap hipertensi ringan dengan tingkat keparahan 1 yaitu sebesar Rp2.591.600 untuk kelas 1, Rp2.221.400 untuk kelas 2, dan Rp1.851.200 untuk kelas 3. ${ }^{8}$ Sementara itu RSUD Panembahan Senopati merupakan salah satu rumah sakit yang bergabung dengan BPJS Kabupaten Bantul sebagai rumah sakit rujukan untuk melayani pasien yang terdaftar dalam JKN sesuai dengan Peraturan Menteri Kesehatan Nomor 1 Tahun 2012 dan Peraturan Gubernur Nomor 59 Tahun 2012 tentang Rujukan Berjenjang. RSUD Panembahan Senopati telah ditetapkan sebagai rumah sakit berstatus Badan Layanan Umum Daerah (BLUD). Status tersebut memberikan keleluasaan bagi RSUD Panembahan Senopati untuk mengelola keuangan sendiri. Tanggung jawab pengelolaan keuangan yang mandiri dan ditambah dengan adanya sistem JKN yang pembiayaannya berdasarkan INA-CBGs maka pihak rumah sakit dituntut untuk melakukan pelayanan yang berkualitas sekaligus efisien. ${ }^{9}$

Penelitian ini bertujuan untuk melakukan komparasi tarif klaim INA-CBGs dengan tarif riil yang dikeluarkan oleh rumah sakit. Analisis ini penting dilakukan agar rumah 
sakit dapat memperoleh gambaran mengenai sistem pembiayaan yang telah dilakukan, sehingga tidak mengalami kerugian.

\section{Metode}

Jenis penelitian ini termasuk dalam evaluasi ekonomi sederhana yang menggambarkan bagaimana perbedaan antara biaya riil (rumah sakit) dengan tarif INA-CBGs pasien rawat inap kelas 1, kelas 2, dan kelas 3 menderita penyakit hipertensi kode I-4-17-1. Penelitian mengambil perspektif rumah sakit sebagai penyedia pelayanan kesehatan, dengan metode pengambilan data yakni secara retrospektif yang diambil dari penelusuran dokumen rekam medik dan data keuangan rumah sakit.

Tempat penelitian adalah bagian instalasi rekam medik, instalasi farmasi, dan bagian keuangan RSUD Panembahan Senopati. Data pasien yang digunakan yaitu data periode 10 bulan (Oktober 2016-Juli 2017). Penelitian ini dilakukan selama 10 bulan berdasarkan Peraturan Presiden Nomor 19 Tahun 2016 tentang perubahan Peraturan Presiden Nomor 12 Tahun 2013 tentang Jaminan Kesehatan yang mulai berlaku Oktober 2016, sedangkan data pada penelitian ini diambil pada Agustus 2017.

Sampel yang digunakan dalam penelitian ini adalah seluruh pasien peserta JKN pada periode Oktober 2016-Juli 2017 di RSUD Panembahan Senopati yang telah memenuhi kriteria inklusi, yaitu meliputi pasien rawat inap kelas 1, kelas 2, dan kelas 3 yang menderita hipertensi dengan kode I-4-17-1. Kriteria eksklusi meliputi data rekam medis yang tidak menyantumkan identitas secara lengkap, dan diagnosis dan data laboratorium yang tidak tersedia. Pasien yang pulang paksa dan meninggal dunia masuk dalam kriteria eksklusi.

Total sampel pada penelitian ini yaitu 53 pasien. Data yang digunakan dalam penelitian ini adalah data sekunder yang diperoleh dari berkas rekam medis bagian keuangan RSUD Panembahan Senopati. Teknik pengumpulan data yakni dengan cara pengamatan secara langsung. Instrumen penelitian yang digunakan berupa tabel pengolah data.

Analisis data dilakukan dengan uji statistik one sample t-test untuk membandingkan tarif riil perawatan pasien rawat inap kelas 1, kelas 2, dan kelas 3 dengan tarif INA-CBGs. Penelitian ini telah mendapatkan izin dari pihak RSUD Panembahan Senopati. Selain itu, penelitian ini juga telah mendapatkan persetujuan laik etik dari Komisi Etik Fakultas Kedokteran Gigi Universitas Gadjah Mada dengan nomor referensi 001151/KKEP/FKG -UGM/EC/2017.

\section{Hasil}

Terdapat total 53 pasien yang menjalani rawat inap hipertensi kode I-4-17-1 periode Oktober 2016 sampai dengan Juli 2017 di RSUD Panembahan Senopati. Semua pasien memenuhi kriteria inklusi dengan pembagian jumlah pasien pada kelas 1 sebesar 12 pasien, kelas 2 sebesar 8 pasien, dan pasien kelas 3 dengan jumlah paling banyak yaitu sebesar 33 pasien. Pasien hipertensi rawat inap kelas 3 paling dominan. Pasien yang terdaftar sebagai anggota BPJS kelas 3 yaitu Peserta Bukan Penerima Upah (PBPU) dan Bukan Pekerja (BP). ${ }^{10}$

Penelitian dilakukan dengan melihat biaya pasien rawat inap hipertensi dengan kode I-4-17-1. Biaya riil rawat inap setiap kelas perawatan antara pasien rawat inap kelas 1 , kelas 2, dan kelas 3 menunjukkan hasil yang berbeda-beda seperti yang terlihat pada Tabel 1. Rata-rata biaya riil yang dikeluarkan rumah sakit melebihi tarif klaim INA-CBGs. Biaya riil pada pasien kelas 1 yakni Rp3.800.403, kelas 2 Rp2.960.900, dan kelas 3 Rp2.171.850. Tabel 1 juga menunjukkan adanya perbedaan yang bermakna antara biaya riil yang harus dikeluarkan rumah sakit pada setiap kelas 
Tabel 1 Biaya Pasien Hipertensi Antarkelas Perawatan

\begin{tabular}{lccc}
\hline & Kelas 1 & Kelas 2 & Kelas 3 \\
\hline Biaya Pasien Hipertensi Rawat Inap & & & \\
Tarif INA-CBGs (Rp) & 2.591 .600 & 2.221 .400 & 1.851 .200 \\
Rata-rata tarif rumah sakit (Rp) & 3.800 .403 & 2.960 .900 & 2.171 .850 \\
Nilai-p & $0,039^{*}$ & 0,454 & 0,077 \\
Perbandingan Tarif Tertinggi dan Terendah Hipertensi Rawat Inap & & \\
Tarif INA-CBGs (Rp) & 2.591 .600 & 2.221 .400 & 1.851 .200 \\
Tarif rumah sakit (tertinggi (Rp)) & 7.976 .265 & 9.016 .833 & 4.880 .536 \\
Tarif rumah sakit (terendah (Rp)) & 1.292 .578 & 925.718 & 899.969 \\
\hline *p $<0,05$ (ada perbedaan signifikan) & & &
\end{tabular}

perawatan terhadap tarif klaim INA-CBGs yang ditunjukkan berdasarkan hasil analisis statistika uji one sample t-test dengan taraf kepercayaan $95 \%$, bahwa nilai p untuk kelas 1 yaitu sebesar $0,039(\mathrm{p}<0,05)$, sedangkan nilai $p$ untuk kelas 2 dan kelas 3 menunjukkan bahwa tidak ada perbedaan yang bermakna $(p>0,05)$. Perbedaan bermakna disebabkan oleh perbedaan biaya pasien hipertensi rawat inap antarkelas perawatan. Data pada Tabel 1 juga menunjukkan terdapat biaya perawatan pasien hipertensi yang lebih tinggi jika dibandingkan tarif klaim INA-CBGs, namun juga terdapat tarif riil yang lebih rendah dibandingkan tarif INA-CBGs. Pada biaya perawataan kelas 1 , didapatkan hasil jumlah biaya riil terbesar yaitu Rp7.976.265 dan biaya riil terkecil yaitu Rp1.292.578; biaya perawatan kelas 2 dengan biaya riil terbesar yaitu Rp9.016.833 dan biaya riil terkecil yaitu Rp925.718; biaya perawataan kelas 3 dengan biaya riil terbesar yaitu $\mathrm{Rp} 4.880 .536$ dan biaya riil terkecil yaitu Rp899.969.

Hasil perbandingan antara total biaya riil rumah sakit dengan total tarif INA-CBGs pada Tabel 2 menunjukkan bahwa total biaya riil rumah sakit lebih besar jika dibandingkan total tarif INA-CBGs. Selisih perbedaan antara total biaya riil rumah sakit dengan total tarif paket INA-CBGs pada ketiga kelas perawatan menunjukkan selisih negatif yakni sebesar Rp30.993.964. Selisih biaya terhadap ketiga kelas perawatan dilakukan analisis statistika uji independent t-test dan menghasilkan nilai $\mathrm{p}<0,05(0,016)$ yang menunjukkan secara umum terdapat perbedaan bermakna antara biaya riil yang dikeluarkan oleh rumah sakit berbanding tarif klaim INA-CBGs.

Tabel 2 Perbandingan Total Tarif INA-CBGs

\begin{tabular}{lcccc}
\hline & Kelas 1 & Kelas 2 & Kelas 3 & Jumlah \\
\hline Jumlah Pasien & 12 & 8 & 33 & 53 \\
Total Biaya Riil (Rp) & 45.604 .840 & 23.678 .062 & 71.671 .062 & 140.953 .964 \\
Total Biaya Riil Rumah Sakit dengan Total Tarif INA-CBGs & & \\
Total tarif paket INA-CBGs (Rp) & 31.099 .200 & 17.771 .200 & 61.089 .600 & 109.960 .000 \\
Selisih paket (negatif) (Rp) & 14.505 .640 & 5.906 .862 & 10.581 .462 & 30.993 .964 \\
p & & & $0,016^{*}$ & \\
Biaya Penggunaan Obat Pasien Hipertensi Rawat Inap & & & \\
Total biaya obat (Rp) & 45.604 .840 & 23.678 .062 & 71.671 .062 & 140.953 .964 \\
Persentase biaya untuk obat (\%) & 12.411 .005 & 8.104 .726 & 16.494 .881 & 37.010 .612 \\
Jumlah Pasien & 27.2 & 34.2 & 23 & 26.3 \\
*p $<0,05$ (ada perbedaan signifikan) & & & &
\end{tabular}


Tabel 3 Selisih Kerugian Pasien Hipertensi Rawat Inap

\begin{tabular}{lcc}
\hline & Jumlah Pasien & Nilai (Rp) \\
\hline Kelas 1 & & 39.485 .511 \\
Kerugian & 3 & 6.119 .329 \\
Keuntungan & & 33.366 .182 \\
Selisih kerugian & 3 & \\
Kelas 2 & 3 & 16.214 .608 \\
Kerugian & 5 & 7.472 .595 \\
Keuntungan & & 8.742 .013 \\
Selisih kerugian & & \\
Kelas 3 & 16 & 45.503 .924 \\
Kerugian & 17 & 26.167 .138 \\
Keuntungan & & 19.336 .786 \\
Selisih kerugian & & \\
\hline
\end{tabular}

Apabila dilihat dari total biaya penggunaan obat berdasarkan Tabel 2, diketahui jumlah biaya riil pasien hipertensi rawat inap untuk ketiga kelas perawatan ialah Rp140.953.964, sedangkan total biaya yang dikeluarkan untuk biaya obat ialah Rp37.010.612. Biaya untuk obat yang dikeluarkan RSUD Panembahan Senopati rata-rata persentase sebesar $26,3 \%$, sehingga $73,7 \%$ digunakan untuk komponen biaya yang lainnya.

Jika biaya yang dikeluarkan rumah sakit untuk pelayanan pasien hipertensi rawat inap melebihi tarif klaim INA-CBGs, rumah sakit akan mengalami kerugian, sedangkan jika biaya perawatan yang dikeluarkan kurang dari tarif klaim INA-CBGs, rumah sakit akan memperoleh keuntungan. Tabel 3 menunjukkan bahwa pada ketiga kelas perawatan, biaya dengan tarif riil yang dikeluarkan lebih tinggi dibandingkan tarif klaim INA-CBGs. Pada pasien kelas 1 , terdapat 9 pasien dengan nilai tarif riil lebih tinggi dibandingkan tarif INACBGs dengan nilai Rp39.485.511, sedangkan terdapat 3 pasien dengan tarif riil lebih rendah dibandingkan tarif INA-CBGs dengan nilai Rp6.119.329 sehingga selisih kerugian sebesar Rp33.366.182. Pada pasien kelas 2 dan kelas 3 juga menunjukkan terdapat selisih kerugian yang dikeluarkan rumah sakit walaupun jumlah pasien dengan biaya riil melebihi tarif klaim INA-CBGs lebih kecil dibandingkan pasien dengan biaya riil kurang dari tarif klaim INACBGs; selisih tersebut sebesar Rp8.742.013 untuk kelas 2 dan Rp19.336.786 untuk kelas 3.

\section{Pembahasan}

Hipertensi merupakan salah satu penyakit degeneratif yang memiliki angka kejadian terbanyak di RSUD Panembahan Senopati. Data grafik dari Dinas Kesehatan Kabupaten Bantul pada tahun 2016 menunjukkan bahwa pasien terbanyak merupakan pasien penyakit essential primary hypertension. ${ }^{11}$

Berdasarkan pedoman INA-CBGs tahun 2016, tarif untuk kode I-4-17-1 pada pasien kelas 1 yaitu sebesar Rp2.591.700, kelas 2 Rp2.221.400, dan kelas 3 Rp1.851.200. ${ }^{6}$ Hasil pada Tabel 1 menunjukkan bahwa pada ketiga kelas perawatan total biaya riil rumah sakit pasien hipertensi rawat inap dengan kode I-4-17-1 melebihi tarif klaim INACBGs dengan perbedaan signifikan terletak pada kelas 1. Penelitian yang dilakukan oleh Padmawati et al. pada tahun 2014 juga menunjukkan tarif rumah sakit lebih besar dibandingkan tarif INA-CBGs pada pasien rawat inap kelas 1 sebanyak 63\%, kelas 2 
sebanyak 48\%, dan kelas 3 sebanyak 39\%. Semakin tinggi kelas rawat inap, semakin tinggi tarif rumah sakit yang dikeluarkan berbanding tarif INA-CBGs. ${ }^{12}$

Sementara itu, adanya selisih negatif pada Tabel 2 menandakan biaya perawatan pasien hipertensi rawat inap yang dikeluarkan oleh rumah sakit lebih besar jika dibandingkan klaim tarif INA-CBGs sehingga rumah sakit sebagai pemberi pelayanan kesehatan dapat mengalami kerugian. Pihak rumah sakit perlu melakukan evaluasi agar perawatan yang diberikan kepada pasien rawat inap memang benar dibutuhkan oleh pasien dan sesuai, dan kendali biaya sangat diperlukan untuk menghindari kerugian rumah sakit dalam klaim tarif INA-CBGs.

Evaluasi terhadap petugas koding rumah sakit juga diperlukan agar kode yang dimasukkan sesuai dengan perawatan dan diagnosis dari pasien. Hal ini didukung oleh penelitian Puspitasari et al. bahwa dari 540 kode diagnosis, sebesar 33\% menunjukkan ketidaktepatan dalam pemberian kode. ${ }^{13}$ Proses koding merupakan hal yang sangat berpengaruh terhadap tarif klaim perawatan pasien karena tarif yang akan diklaim BPJS sesuai dengan tarif kode yang dimasukkan petugas koding. Seperti yang telah diatur dalam Peraturan Menteri Kesehatan Republik Indonesia Nomor 27 Tahun 2014 bahwa untuk hipertensi terdapat 3 kode berdasarkan tingkat keparahannya, yaitu 1-4-17-I untuk hipertensi ringan, 1-4-17-II untuk hipertensi sedang dan I-4-17-III untuk hipertensi berat. ${ }^{14}$

Hasil penelitian pada Tabel 3 menunjukkan bahwa pada ketiga kelas perawatan, jumlah pasien dengan biaya perawatan lebih tinggi dari tarif INA-CBGs lebih besar dibandingkan dengan jumlah pasien dengan biaya perawatan yang sesuai dengan tarif INA-CBGs sehingga menghasilkan selisih negatif dan dapat menyebabkan kerugian rumah sakit. Biaya perawatan yang melebihi rata-rata tersebut harus mendapatkan perhatian dari manajemen rumah sakit dengan cara melakukan evaluasi dan perbaikan metode pelayanan yang lebih efisien dengan tetap memperhatikan mutu pelayanan kesehatan.

Tarif dan kualitas pelayanan adalah hal yang saling berhubungan. Rumah sakit harus mengoptimalkan hubungan antara biaya dan kualitas pelayanan kesehatan yang seimbang agar efisiensi dapat terjadi. ${ }^{15}$ Salah satu upaya guna meningkatkan efisiensi ialah rumah sakit harus memiliki clinical pathway untuk setiap diagnosis penyakit sebagai sebuah acuan dalam memberikan pelayanan medis pada pasien. ${ }^{16}$ Acuan pelayanan medis yang digunakan oleh RSUD Panembahan Senopati ialah Standar Pelayanan Medis (SPM), namun terdapat dua jenis penyakit yang tidak memiliki SPM tentang penatalaksanaan pengobatannya, yaitu hipertensi dan diabetes melitus. Hal ini dapat melatarbelakangi kurang diterapkannya kendali mutu dan kendali biaya di RSUD Panembahan Senopati. Menurut Munawaroh et al. tahun 2019, strategi rumah sakit dalam upaya meningkatkan mutu pelayanan dan efisiensi biaya rumah sakit antara lain dengan menerapkan clinical pathway sebagai upaya kendali mutu dan biaya sehingga peningkatan efisiensi organisasi dalam peningkatan kualitas kesehatan dapat terjadi. ${ }^{16,17}$

Sementara itu, penelitian yang dilakukan Rahajeng et al. pada tahun 2014 menunjukkan bahwa biaya total yang dikeluarkan pihak RS PKU Muhammadiyah Yogyakarta untuk pasien hipertensi pada kode diagnosis I-417-I, I-4-17-II dan I-4-17-III periode Januari 2014-Desember 2014 memiliki perbedaan yang signifikan dengan biaya yang ditetapkan pemerintah dalam BPJS Kesehatan, namun rata-rata biaya riil pada semua kelas terapi lebih kecil dibanding pembiayaan kesehatan berdasarkan tarif INA-CBGs dengan selisih positif sebesar Rp26.449.116 untuk kode I-417-I. ${ }^{18}$ Sedangkan pada diagnosis penyakit yang berbeda yaitu stroke iskemik, penelitian yang dilakukan oleh Munawaroh et al. pada 
tahun 2018 memperoleh hasil yang sama dengan penelitian ini, yaitu total biaya rumah sakit lebih besar dibanding tarif INA-CBGs dengan selisih tarif Rp116.374.330. ${ }^{16} \mathrm{Hal}$ ini menandakan bahwa untung atau ruginya pembiayaan kesehatan berdasarkan tarif INACBGs tergantung pada manajemen masingmasing rumah sakit.

Keterbatasan pada penelitian ini adalah cakupan yang dinilai, yaitu tarif klaim INACBGs hanya pada kasus hipertensi dengan kode I-4-17-I, sehingga hal ini belum secara global menilai perbedaan biaya riil rumah sakit dengan tarif klaim INA-CBGs. Selain itu, penelitian ini dilakukan di satu provider atau penyedia pelayanan kesehatan yaitu RSUD Panembahan Senopati, sehingga perlu dilakukan penelitian lebih lanjut dengan kode INA-CBGs yang berbeda dan tempat pelayanan kesehatan yang berbeda.

\section{Simpulan}

Total biaya riil yang dikeluarkan oleh RSUD Panembahan Senopati lebih besar dibanding tarif klaim INA-CBGs. Besarnya perbedaan antara biaya riil dengan tarif paket INA-CBGs yaitu sebesar negatif Rp30.993.964. Terdapat perbedaan bermakna pada besar biaya riil yang dikeluarkan rumah sakit terhadap tarif INA-CBGs pada pasien kelas 1 dengan nilai signifikansi $\mathrm{p}<0,05(0,039)$. Persentase total biaya rumah sakit yang digunakan untuk komponen biaya obat yakni sebesar $26,3 \%$. Kondisi total tarif riil rumah sakit yang lebih besar dapat disebabkan oleh kesalahan dalam melakukan kode dan tidak adanya clinical pathway yang ada di rumah sakit.

\section{Ucapan Terima Kasih}

Terima kasih kepada bagian rekam medis, keuangan, dan farmasi RSUD Panembahan Senopati atas bantuannya dalam pengambilan data penelitian.

\section{Pendanaan}

Penelitian ini tidak didanai oleh sumber hibah manapun.

\section{Konflik Kepentingan}

Seluruh penulis menyatakan tidak terdapat potensi konflik kepentingan dengan penelitian, kepenulisan (authorship), dan atau publikasi artikel ini.

\section{Daftar Pustaka}

1. Peltzer K, Pengpid S. The prevalence and social determinants of hypertension among adults in Indonesia: A crosssectional population-based national survey. Int J Hypertens. 2018;2018:56107 25. doi: $10.1155 / 2018 / 5610725$

2. Kaliyaperumal S, Hari SB, Siddela PK, Yadala S. Assessment of quality of life in hypertensive patients. J Appl Pharm Sci. 2016;6(5):143-7. doi: 10.7324/JAPS .2016.60522

3. Badan Penelitan dan Pengembangan Kesehatan Republik Indonesia. Hasil utama riset kesehatan dasar 2018. Jakarta: Kementerian Kesehatan Republik Indonesia; 2018.

4. Badan Penyelenggara Jaminan Sosial (BPJS) Kesehatan. Ringkasan eksekutif pengelolaan program dan laporan keuangan jaminan sosial kesehatan [Diakses pada: 26 Oktober 2019]. 2016. Tersedia dari: https://www.bpjs-kesehat an.go.id/bpjs/dmdocuments/b39df9ae7a3 0a5c7d4bd0f54d763b447.pdf

5. Kementerian Kesehatan Republik Indonesia. Peraturan Menteri Kesehatan Nomor 52 Tahun 2016 Tentang Standar Tarif Pelayanan Kesehatan Dalam Penyelenggaraan Program Jaminan Kesehatan. Jakarta: Kementerian Kesehatan Republik Indonesia; 2016.

6. Kementerian Kesehatan Republik Indonesia. 
Peraturan Menteri Kesehatan Nomor 76 Tahun 2016 Tentang Pedoman Indonesian Case Base Groups (INA-CBG) Dalam Pelaksanaan Jaminan Kesehatan Nasional. Jakarta: Kementerian Kesehatan Republik Indonesia; 2016.

7. Presiden Republik Indonesia. Peraturan Presiden Republik Indonesia Nomor 12 Tahun 2013 Tentang Jaminan Kesehatan; 2013.

8. Presiden Republik Indonesia. Peraturan Presiden Nomor 19 Tahun 2016 Tentang Jaminan Kesehatan; 2016.

9. Kementerian Kesehatan Republik Indonesia. Laporan akuntabilitas kinerja Kementerian Kesehatan tahun 2013. Jakarta: Kementerian Kesehatan Republik Indonesia; 2013.

10. Badan Penyelenggara Jaminan Sosial (BPJS) Kesehatan. Panduan layanan bagi peserta Jaminan Kesehatan Nasional. Jakarta: Badan Penyelenggara Jaminan Sosial (BPJS) Kesehatan; 2018.

11. Dinas Kesehatan Bantul. Profil kesehatan Kabupaten Bantul 2019. Bantul: Dinas Kesehatan Bantul; 2019.

12. Padmawati NNA, Pujiyanto. Analisis perbandingan antara biaya pelayanan pasien rawat jalan dan rawat inap berdasarkan tarif rumah sakit dengan tarif INA-CBG pada Program Jaminan Kesehatan Nasional di RSU Zahirah bulan pelayanan Januari hingga Mei 2014 [Diakses pada: 4 November 2020]. Tersedia dari: http://jkn.jamsosindonesia. com/home/cetak/1110/Analisis $\% 20$ Perbandingan $\% 20$ Antara $\%$ 20Biaya $\% 20$ Pelayanan \%20Pasien\%20Rawat\%20 Jalan\%20Dan\%20Rawat\%20Inap\%20 Berdasarkan\%20Tarif\%20Rum

13. Puspitasari N, Kusumawati DR. Evaluasi tingkat ketidaktepatan pemberian kode diagnosis dan faktor penyebab di Rumah Sakit X Jawa Timur. J Manaj Kesehat Yayasan RS Dr. Soetomo. 2017;3(2)1-12. doi: 10.29241/jmk.v3i1.77

14. Kementerian Kesehatan Republik Indonesia. Peraturan Menteri Kesehatan Nomor 27 Tahun 2014 Tentang Petunjuk Teknis Sistem Indonesian Case Base Groups. Jakarta: Kementerian Kesehatan Republik Indonesia; 2014.

15. Pross C, Strumann C, Geissler A, Herwartz H, Klein N. Quality and resource efficiency in hospital service provision: A geoadditive stochastic frontier analysis of stroke quality of care in Germany. PLoS One. 2018;13(9):1-30. doi: 10.1371/jour nal.pone. 0203017

16. Munawaroh S, Sulistiadi W, Rachmad R. Perbedaan tarif INA-CBG's dengan tarif riil rumah sakit pada pasien BPJS kasus stroke iskemik rawat inap kelas I di RS PON tahun 2018. J Manaj Admin Rumah Sakit Indones. 2019;3(2):155-65.

17. Lawal AK, Rotter T, Kinsman L, Machotta A, Ronellenfitsch U, Scott $\mathrm{SD}$, et al. What is a clinical pathway? Refinement of an operational definition to identify clinical pathway studies for a Cochrane systematic review. BMC Med. 2016;14:35. doi: 10.1186/s12916-016-05 $80-\mathrm{z}$

18. Rahajeng B, Maziyyah N, Hapsari CW, Krisnawati L. Analisis biaya pengobatan hipertensi sebagai pertimbangan dalam penetapan pembiayaan kesehatan berdasarkan INA-CBGs pada program Jaminan Kesehatan Nasional 2014 di Rumah Sakit PKU Muhammadiyah Yogyakarta. Yogyakarta: Laporan Penelitian Universitas Muhammadiyah Yogyakarta; 2014.

(C) 2021 Nilansari et al. The full terms of this license incorporate the Creative Common Attribution-Non Commercial License (https://creative commons.org/licenses/by-nc/4.0/). By accessing the work you hereby accept the terms. Non-commercial use of the work are permitted without any further permission, provided the work is properly attributed. 